specimen showing papillomata as low as the bifurcation of the trachea. The differential diagnosis of true papillomata from excrescences resembling them, especially in the region of the tonsil, was also demonstrated.

Several specimens of pachydermia laryngis were shown; its etiology and relation to syphilis and tuberculosis were dealt with.

Of the more unusual growths, the demonstration included specimens of so-called fibroma of the ventricle of the larynx, and its clinical resemblance to prolapse of the mucous membrane lining the ventricle was illustrated.

Dr. Henington Pegler read a paper on abeyance of nasal breathing attributable to functional derangement of the soft palate. This paper will be found reported on p. 337 .

Mr. Richard Lake read a short paper on the indications for the removal of adenoids, and showed some very interesting specimens.

Mr. J.H. Chaldecotт read a paper on the choice of an anæsthetic for operations upon the ear, nose, and throat. He strongly condemned the use of chloroform in these operations, but unfortunately there was no time to discuss the paper.

Dr. Frederick Spicer showed some cases of disease of the accessory sinuses of the nose presenting unusual features.

\title{
Abstracts.
}

\section{NOSE AND NASO-PHARYNX.}

Choussaud.-Paraffin Injections. " Revue Hebdom. de Laryngologie," etc., March 29, 1902.

The paraffin which was first used for subcutaneous injection consisted of a mixture of soft and hard paraffin, with a melting-point of $40^{\circ}$ C. $\left(104^{\circ}\right.$ F.). The results obtained from its use have not always been satisfactory, and in some cases not free from danger. Thus, two cases of embolism have been reported; in many cases the paraffin has spread out into the surrounding tissues, whilst in others the swelling originally produced has, later on, gradually decreased in size. This last circumstance is probably due to a gradual absorption of the soft paraffin, only the hard paraffin remaining permanently in situ. To overcome these difficulties and dangers Eckstein uses a paraffin, probably not a mixture of two members of the methane series, but one of the higher members of the series. It has a meltingpoint of about $60^{\circ} \mathrm{C}$. $\left(140^{\circ} \mathrm{F}\right.$.). The syringe should be covered with india-rubber to prevent rapid cooling, the syringe and needle should be heated to a temperature rather above $140^{\circ} \mathrm{F}$, and the injection must be done quickly. The injection is painful, but the results appear to be permanent, the paraffin being soon encapsuled. So far as the author is aware no bad effects have been produced. Arthur J. Hutchisont. 


\section{Jousset.-Nasal Vertigo and Epilepsy. " Revue Hebdom. de Laryngol.," etc., March 15, 1902.}

In the Lyon Medical of November, 1901, Dr. Collet published the case of a patient who suffered from epileptiform attacks. The patient suddenly felt a pricking in the nose, followed or not by sneezing, then a violent pain in the back of the neck, almost immediately thereafter he lost his balance and fell face downward. There was time to stretch out the hands to break the fall; consciousness was not completely lost. The face, at first congested, became very pale for some minutes; abundant perspiration came on and lasted a quarter of an hour. The patient remained somnolent and depressed the rest of the evening. This case Jousset regards as one of epilepsy with nasal aura.

Two similar cases have come under his observation: (1) A man, aged twenty-six, consulted Jousset on account of slight difficulty of respiration. At times he had pricking sensations in the left nasal fossa, followed by heaviness in the head, formication in the limbs, and slight loss of consciousness. The face, at first congested, became very pale, and the patient was greatly depressed after an attack. The septum was found to be badly deflected to the left, and the right inferior turbinal was hypertrophied, and a perforation existed in the right membrana tympani. After an operation, which established free respiration on both sides of the nose, the crises disappeared.

(2) Male, aged thirty, had been subject to epileptic attacks. A course of treatment with bromides had improved his condition considerably, but of late the attacks were becoming again more frequent. The patient attributed the return of his attacks to the onset of pains in the nose. The pain was followed by troublesome secretion. Examination revealed hypertrophic rhinitis in the left, atrophic in the right side. These conditions were treated by galvano-cautery and douches. The crises ceased, and have not returned.

Arthur J. Hutchison.

\section{Phillips, Sidney.-Pheumatism as a Cause of Epistaxis in Children. "Lancet," February 22, 1902.}

Ten cases are quoted to show the association of rheumatism and epistaxis. In all these cases the urine was carefully examined, and it was found to be free from albumen. There was no local nasal disease, and no cause could be found $\mathrm{fc}^{-}$the epistaxis except that there were evidences of a rheumatic diathesis. The author could bring forward many other cases similar to the above. In some of them the epistaxis came on with an attack of acute rheumatism; in others epistaxis alternated with attacks of articular inflammation or was preceded by them, and in some cases it occurred in connection with chorea, which was presumably rheumatic. That in children synovial effusion into joints and articular rheumatism may occur without any pain has often been pointed out, but it is even now scarcely sufficiently remembered; and if the joints were examined in some cases of epistaxis a clue would be often found to the cause of the latter.

Epistaxis is one of the toxic effects of salicylates given internally. Dr. L. Shaw ${ }^{1}$ found that it occurred in 11 patients of 174 under the treatment of rheumatism by salicylates. None of the patients referred to, however, had taken salicylates before the epistaxis occurred, and all but one, who did not respond to it, took the salicylate with good

$$
{ }^{1} \text { Guy's Hospital Reports, } 188 \text { i. }
$$


result. It is possible that in some cases of rheumatism treated by salicylates where epistaxis occurs it is due to the disease, and not to the drug.

In all the literature on rheumatism the author has not found any suggestion that rheumatism may cause epistaxis except indirectly, through setting up endocardial changes. In a very excellent article on epistaxis by Dr. F. de Havilland Hall ${ }^{1}$ various alterations in the blood are mentioned which are attended with epistaxis as a prominent symptom-viz., hæmophilia, purpura, scurvy, chlorosis, anæmia, pernicious anæmia, and malarial poisoning, but not the rheumatic diathesis. The only suggestion that rheumatism has any influence whatever in the causation of epistaxis is in a paper by Dr. Rendu² of Paris, quoted by Dr. Hall, in which it is said that epistaxis may occur in young persons who become later the subjects of piles or rheumatism. It may be said that epistaxis occurs in the young who are already the subjects of rheumatism.

There is nothing inherently improbable in the supposition to which many cases point that rheumatism may give rise to epistaxis, for many other blood states are acknowledged to do so, and rheumatism is a known cause of one variety of purpura in which hæmorrhages occur from cutaneous and mucous surfaces.

StClair Thomson.

Stuart-Low, W.-The Topical Application of Mucin in certain Affections of the Nose, Throat, and Ear. " Lancet," April 5, 1902.

The bete noire of nose, throat, and ear practice is the difficulty of successfully accomplishing amelioration of aridity of the mucous linings of these organs, and the fact is that to such aridity all the other intractable, disagreeable, and distressful symptoms are due-namely, incrustation, fetor, ulceration, hæmorrhage, and pain. The lessened mucous flow by causing desiccation causes also the loss of the essential and special nasal functions of smell and the filtration and warming of the inspired air. It is claimed for mucin that it does more than anything that has yet been tried to relieve the discomfort in mild cases and to mitigate the distress and suffering in the more severe. It is a natural remedy which restores the moisture and maintains it in virtue simply of its hygroscopic properties.

When applied locally to the interior of the nose and pharynx mucin has a soothing and emollient action; it moistens the surface and softens incrustations, readily facilitates their removal, and prevents their re-formation; it thus also obviates fœetor, which is one of the best points in its favour as a local remedy. Mucin also restores the nasal function of smell by its hygroscopic effect, and the filtration and warming functions are also resumed, because in a dry condition the mucous membrane is functionless. Messrs. Burroughs, Wellcome and Company have prepared a soloid composed of 5 grains of mucin, 5 grains of sodium bicarbonate, and 1 grain of menthol. This is prepared for use by dissolving it in 1 ounce of sterilized warm water, or to get more of the mucin thoroughly into solution the author is in the habit of dissolving the soloid in equal parts of sterilized warm water and sterilized warm lime-water. This solution may be used to spray, to douche, or to syringe the nose and throat twice daily. The spray should be a coarse one, as otherwise it is liable to get clogged with particles of undissolved mucin. A very good plan to obviate this

1 Westminster Hospital Reports, 1893.

2 La Semaine Médicale, June, 1884. 
is to spray warm water at least once a day through the instrument and thus wash it out. If much incrustation has to be got rid of it is well to rub it off with cotton-wool saturated in the warm mucin solution on a mounted prop. In severe and very old-standing cases of atrophic trouble he supplements the local treatment by giving the patient "tabloid mucin co." containing 5 grains each of mucin and sodium bicarbonate internally before and after meals, and thus relieve the concomitant gastric irritation and constipation.

The solution of mucin has also been tried in cases of dry catarrh of the middle ear. The author finds that even long-standing cases of atrophic nasal and pharyngeal trouble do very well, and that the crusts soon cease to accumulate, after regular douching twice daily with a solution of "soloid mucin co.," and that no other irrigations are ordinarily necessary ; but there are certainly instances when pus is present in the discharge in which it is advantageous to use just before the mucin douche a lotion of sodium sulphate or a combination of sodium sulphate and bicarbonate for cleansing purposes. The author has patients who, after years of suffering from typical atrophic rhinitis with all its horrors of fœtor and discomfort, have, after continuous and persistent application of the mucin irrigation, been able to dispense with treatment to a greater extent than two or three times weekly.

StClair Thomson.

Trouchaud.-Malignant Scarlatina, complicated by Empyema of the Accessory Nasal Cavities and of the Right Mastoid. "L'Echo Méd. du Nord," May 18, 1902.

The patient was a boy twelve years old. He had a violent attack of scarlatina, with severe sore throat, copious eruption, and temperature as high as $40.2^{\circ} \mathrm{C}$, but no albuminuria. A small gangrenous area appeared on one cheek and the glands on both sides of the neck were involved. The nose, naso-pharynx, mouth and throat were treated from the onset of the fever with antiseptics. In spite of this, however, purulent rhinitis appeared, and the adenitis on the right side of neck went on to abscess formation, and had to be opened about a fortnight from the onset of the scarlatina. About this time also right-sided conjunctivitis appeared one morning, followed by œdema of the right upper lid. Empyema of the right maxillary antrum and of the right ethmoid cells, and probably of the frontal sinus, was diagnosed. The antrum was opened through the canine fossa, a large counter opening made into the nose, and both wounds left open so as to permit of very free irrigation. Then the ethmoid cells and frontal sinus of the right side were freely opened and drained. In all these cavities pus or sero-pus was found. Dressing was needed twice, and sometimes three times a day, on account of the rapid formation of pus and false membranes. Temperature remained high-from $40 \cdot 5^{\circ}$ at night to $38.8^{\circ}$ or $39^{\circ} \mathrm{C}$. in the morning-and bed-sores began to appear on the buttocks, elbows, trochanters, and inner surface of knees. The odema of the eyelid disappeared and the nasal condition generally improved; still the temperature remained high and the general condition of the patient was grave.

After about a week he complained of great pain in both ears; both tympana were found to be acutely inflamed. The membranes were freely incised and pus evacuated. The left ear recovered quite satisfactorily, but on the right a mastoid operation had to be performed. 
Pus was found in the antrum and at the tip of the process. Thereafter the temperature fell to $38^{\circ}$, rising at night to $39^{\circ}$. After eight days it was normal. The patient commenced to improve, and finally made a complete recovery.

Arthur. J. Hutchison.

\section{Yonge, Eugene S.-The Treatment of Ozana by Cupric Electrolysis.} "Lancet," November 9, 1901.

It was not until the year 1892 that Jouslain ${ }^{1}$ proposed the method of cupric interstitial electrolysis which up to the present date appears to have progressed farthest in the direction of cure. Cheval described the procedure in 1895, and asserted that he had obtained 90 per cent. of cures, the majority of these after a single séance; but a committee appointed to investigate the matter by the Society of Belgian Laryngologists and Otologists, to whom he had communicated his paper, were far from being able to share his optimism. Bayer, ${ }^{2}$ Brindel, Gouguenheim and Lombard, ${ }^{3}$ and $\mathrm{McBride}^{4}$ have all given their experiences of cupric electrolysis.

The author had the opportunity of testing the efficacy of this treatment in fifteen cases, and the details of the method as employed are briefly as follows: The nasal cavities were first thoroughly cleansed by a warm alkaline and antiseptic douche. Cocaine was then applied to the nasal cavity to be treated, and after a few minutes the parts were dried and the electrolysis needles inserted. The copper needle, attached to the positive pole, was passed into the inferior or middle turbinal-usually the former-and the steel needle into the septum. The strength of the current varied, but it was found that from 3 to 10 milliampères were the most suitable intensities, although currents as strong as 20 milliampères were on a few occasions used. As a general rule, the current was allowed to pass for ten minutes, and it appeared that no advantage accrued from prolonging the application beyond this period of time. After each séance the patient was usually instructed to refrain from syringing the nose until the next examination. The number of applications given depended upon the improvement noted; five séances were the maximum.

Although at least one death has been attributed to this treatment, the author did not himself observe any after-effects which were calculated to give rise to alarm. In analyzing his own observations he has divided the cases into (1) those in which the patients were cured; (2) those in which the patients were much improved; (3) those in which the patients were temporarily improved, but relapsed; and (4) those in which the patients were not improved.

1. Cases in which the Patients were Cured.-These were two in number.

2. Cases in which the Patients were Much Improved.-These cases amounted to five, all of whom, with one exception, were seen in October, 1901, and the reports were made at that date.

All the cases were females, and in all except one the disease was bilateral. The patients who suffered from marked atrophic pharyngitis gave the most trouble; and it was observed that whilst the treatment applied to one nostril had a beneficial and, so far as could be ascertained, an equal effect on the other, the action of the remedy on

\footnotetext{
1 Moure: Bullotin de la société Francaise l'otologie, etc., tome xiii., 1. 1.

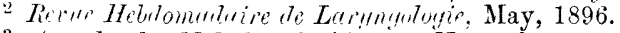

3 Amales tes Mutralies de l'Oreille, November, 1898.

* Edinturgh Metied? . Finmorl. March, 1899.
} 
the dry naso-pharynx was practically nil. The exact means by which the treatment takes effect is still a matter for conjecture. Possibly foetid atrophic rhinitis is a tropho-neurosis which is benefited by the stimulating effect of the electrical current on the part; on the other hand, it may be that the formation of copper salts at the positive pole is the essential factor.

Whilst quite convinced of the relative value of this method of treatment, the author's own small experience leads him to be somewhat diffident of concluding that a permanent cure is to be expected in any but a minority of the cases; and a re-examination, after an interval of several months, of a number of patients who were all too prematurely considered to be cured, has impressed upon him that freedom from symptoms for one, two, or even three months does not insure that a patient shall be free from relapse. At the same time, the benefits of cupric electrolysis appear to be so far superior to those of other procedures that it may be looked upon as the best remedy that has yet been found ; and although for the victims of "ozæna" it will not repair the shrunken turbinals or restore intact the sense of smell, it will, in a certain percentage of cases, so reduce, or even banish, the tendency to fœetid crust-formation that a state of wholesome comfort-the ultima Thule of these unfortunate sufferers-is safely reached.

StClair Thomson.

\section{PHARYNX AND BUCCAL CAVITY.}

Lermoyez, M., and Gasne, G.-Acute Gout of the Pharynx. "Annales des Maladies de l'Oreille, du Larynx, etc.," No. 5, May, 1902.

The authors quote the following interesting case :

M. H- - , forty-eight years of age, had acute articular rheumatism at the age of thirteen, had since travelled all over the world, and had had most of the indigenous fevers, also syphilis ; during the last fifteen years he has been well, with the exception of neurasthenia.

On the night of May 5 he suddenly developed a swelling and redness on the left tonsil, soft palate, and posterior wall of the pharynx. Skin hot ; temperature $101.5^{\circ}$; pulse 120 ; tongue swollen and covered with fur; urine scanty and dark coloured; swallowing difficult.

On May 8 a saline purge was given, which brought a slight temporary improvement of the pain in swallowing.

On May 10 the voice was nasal, and there was regurgitation of fluids through the nose. On the 11th Dr. Lermoyez was called in. There was no glandular enlargement, and peritonsillar abscess was diagnosed; no operation was permitted. On the 12 th the condition was the same. On the 13th the swelling suddenly disappeared, without any fluid discharge, leaving only a general redness. The same night the patient complained of severe pain in his big toe, which developed into an attack of gout with all the classical symptoms. Soda salicylate and colchicum rapidly brought about a cure. gout :

The authors point out the distinguishing symptoms of pharyngeal

1. Sudden onset, acute evolution and sudden disappearance.

2. Sharp febrile symptoms, depression.

3. Very acute pain, out of proportion to local appearances. 